\title{
Effect of Initial Microstructure on Ti-6Al-4V Joint by Friction Stir Welding
}

\author{
Sungook YOON*, Rintaro UEJI, Hidetoshi FUJII
}

Joining and Welding Research Institute, Osaka University,

$$
\text { 11-1, Mihogaoka, Ibaraki, Osaka 567-0047, Japan }
$$

Abstract: Ti-6Al-4V alloy plates with three types of initial microstructures, which have different densities of the high angle boundaries, were joined by friction stir welding (FSW), and the microstructure evolution in the stir zone by the FSW was clarified. Concerning the morphology of the microstructure, all three joints show similar characteristics; the top surface of the SZs exhibited a mixture of the lamellar structure with equiaxed $\alpha$ grains and the area fraction of the equiaxed $\alpha$ grain gradually increased with the increasing distance from the top surface due to the temperature gradient. On the other hand, the mean $\alpha$ grain size of the fully equiaxed $\alpha$ structure area decreased with the increasing initial density of high angle boundaries. This accelerated grain refinement was discussed based on the effect of the inhomogeneous microstructure on the recrystallization.

Keywords: friction stir welding, titanium, microstructure, recrystallization, initial microstructure.

*Corresponding author, E-mail: yoon@jwri.osaka-u.ac.jp, yoonsungook@gmail.com, Tel./fax: +81668798663 . 


\section{Introduction}

The Ti-6Al-4V alloy is one of the most popular titanium (Ti) alloys for practical use since it is a light weight structural material as well as a preferably strong metal whose mechanical properties can be adjusted by various heat treatments. However, the disadvantage of this alloy involves its poor weldability due to the frequent formation of weld defects. One of the possible ways to alleviate this problem is to use the Friction Stir Welding (FSW) which was originally developed by The Welding Institute (TWI) [1]. Since the FSW is completely regarded as a solid state joining process, the undesirable phenomena accompanied with the fusion welding can be omitted. The process technology for the FSW of Ti alloys has been well developed in this decade and some studies have been published on the FSW joint of the Ti-6Al-4V alloys. Concerning with the microstructure of the FSWed Ti-6Al-4V alloy joints, different types of microstructures can be obtained depending on the thermal cycle and the majority studies examined the effect of the welding parameters on the mechanical properties of the joints. For example, Ramirez et al. [2] reported the formation of fine $\beta$ colonies with the lamellar structure in the stir zone (SZ) and they pointed out that optimization of the welding parameters is necessary. Zhang et al. [3] and Su et al. [4] reported that the formation of the fully lamellar structure in the SZ and they pointed out the mechanical properties of the joints increased with the decreasing in the tool rotation rate and increasing in the tool traverse speed. Liu et al. [5], Zhou et al. [6,7] performed FSW or friction stir processing of Ti-6Al-4V plates and reported that the microstructure of the SZ consists of the equiaxed $\alpha$ grains with the $\alpha+\beta$ lamellar structure. Although equiaxed $\alpha$ grain was presented in the SZ, $\beta$ to $\alpha$ transformation occurred during the FSW process. In addition, they clarified that the transverse tensile properties of the joints were inferior to that of the base metal although the mechanical properties of the joints increased with decreasing in the heat input. Recently, 
Kitamura et al. [8] claimed that the FSW performed below the $\beta$-transus temperature provides the equiaxed fine $\alpha$ structure which is preferable for the mechanical properties of the joints. Lienert [9] clarified the temperature gradient in the thickness during the FSW process of a mill annealed Ti-6Al-4V plate. The temperature gradient is one of the characteristic features of the FSW of Ti due to its poor thermal conductivity. Edwards et al. [10] conducted FSW of various thicknesses of the Ti-6Al-4V plates and reported that the grain size of the SZ in thinner plates was finer than those of in the thick plates due to the faster cooling rate. In addition, they clarified that the grain size distribution along thickness of the SZ due to the lower thermal conductivity. Recently, much attention has been paid on the solid state welding of high melting point materials such as steels, Ti, Ti alloys and dissimilar welding between the high melting point materials and other metallic materials [11-14]. Although there are some reported studies as already mentioned, the number of the publications about the FSW of the Ti alloy is limited compared with other materials $[15,16]$.

Based on previous studies, the FSW can be regarded as one of the plastic deformation processes and recrystallization is one of the key metallurgical phenomena for the microstructure development $[17,18]$. On the other hand, the Ti-6Al-4V is categorized as an $\alpha+\beta$ alloy so that the phase transformation should play an important role in the resultant microstructure development. Both the recrystallization and the phase transformation are affected by the amounts of the various kinds of crystallographic lattice defects such as grain boundaries. As already mentioned, most of previous reported studies were clarified the effect of the welding parameters on the joints microstructure and the mechanical properties, however, the Ti-6Al-4V alloy has been heat treated to tailor the mechanical properties, which causes a variation in their initial microstructures. Consequently, the effect of the initial microstructure on the resulting FSW joint 
should be clarified. The aim of this study is to investigate the microstructural features of the Ti6Al-4V FSW joints welded the below the $\beta$-transus temperature whose base metals have various initial microstructures which are prepared by the different preheat treatments.

\section{Experiments}

Ti-6Al-4V plates with a thickness of $5.0 \mathrm{~mm}$ and a width of $50 \mathrm{~mm}$ were used as the base metal (BM). The microstructure of the BM was controlled by the preheat treatment. The asreceived sample was re-heated at $1100^{\circ} \mathrm{C}$ followed by water quenching or furnace cooling. As a result, three kinds of microstructures were obtained. The FSW was performed at a tool rotation rate of $150 \mathrm{rpm}$ and a tool traverse speed of $10 \mathrm{~mm} / \mathrm{min}$. A Co-based alloy tool with a tapershaped probe was used. The dimensions of the tool were a $25 \mathrm{~mm}$ shoulder diameter, a $4.9 \mathrm{~mm}$ probe length and a probe tip diameter of $3.4 \mathrm{~mm}$ was used for the FSW. The tool rotation axis was tilted by $1^{\circ}$ to the tool traverse direction and argon shielding gas was continuously supplied in order to prevent oxidation of the joints. Before the FSW, the microstructural features of the BMs were examined by scanning electron microscopy (SEM), electron back scattering diffraction (EBSD) and X-ray Diffraction (XRD). The microstructure observations of the joints were carried out by optical microscopy (OM), SEM, EBSD and transmission electron microscopy (TEM). The contaminated areas in the SZ were examined by an energy dispersive spectroscopy (EDS) analysis system. The joints were cut perpendicular to the welding direction and the cross section was ground. The specimen for the $\mathrm{OM}$ observation was etched in a $2 \mathrm{ml}$ $\mathrm{HF}+6 \mathrm{ml} \mathrm{HNO}_{3}+92 \mathrm{ml}$ water solution. The specimen for the SEM and the EBSD observations

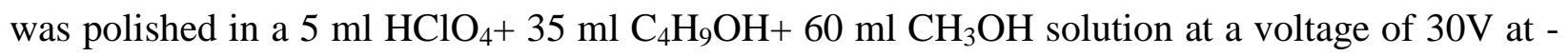
$40^{\circ} \mathrm{C}$. EBSD mappings were conducted at a scan area of $40 \mu \mathrm{m} \times 110 \mu \mathrm{m}$ and a step size of $0.2 \mu \mathrm{m}$. 
The mean high angle boundary length per unit area $\left(\mathrm{L}_{\mathrm{HAGB}}\right)$ was defined using the following equation:

$L_{H A G B}=\frac{1}{\sqrt{3}} \cdot \frac{n_{H A G B} \times S}{A_{S}}$

where $1 / \sqrt{ } 3$ is the hexagonal grid factor, $n_{\mathrm{HAGB}}$ is the total number of boundaries whose interpixel misorientationis above $15^{\circ}$, $\mathrm{s}$ is the step size and $\mathrm{A}_{\mathrm{s}}$ is the scan area. Vickers hardness tests were conducted on the cross-section perpendicular to the tool traverse direction. The hardness test was carried out along the transverse direction (TD) at the center in thickness with a load of $200 \mathrm{~g}$ for a duration time of $15 \mathrm{~s}$.

\section{Results and discussion}

\subsection{Microstructure of base metal}

Figure 1 shows the backscattered electron images of Fig. 1(a) the as-received material, (b) the furnace-cooled material and (c) the water-quenched material. The microstructure of the asreceived material consisted of elongated coarse $\alpha$ grains with fine equiaxed $\alpha$ grains. The microstructures of both the furnace-cooled and the water-quenched materials exhibited elongated structures. . The spacing of the $\alpha$ plates in the water-quenched material was much smaller than that of the furnace-cooled material. The EBSD measurements clarify the difference among the BMs more clearly. Figure 2 shows the orientation color maps of the BMs. In the furnace-cooled material, the prior $\beta$ grains were decorated by the $\alpha$ colonies which have almost the same 
orientations in the specific one $\alpha$ colony. In addition, the black regions between the $\alpha$ plates probably indicate the area of the $\beta$ phase or artifacts of the polishing process where the precise indexing of the EBSD pattern cannot be executed. On the other hand, in the water-quenched material, the lamellar structure having larger aspect ratio $\alpha^{\prime}$ plates than that of the $\alpha$ plates in the furnace-cooled material can be found. It should be also noted that the $\alpha^{\prime}$ plates in the waterquenched material showed randomly changed color distributions compared to the furnace-cooled material indicating the existence of more variants in the water-quenched material. This is the resultant structure by the martensitic transformation due to the rapid cooling. These lamellar morphologies were widely reported in a previous study on Ti-6Al-4V [19]. In order to clarify the influence of the grain boundary characteristics of the BMs on the plastic deformation behavior during the FSW, the high angle grain boundary maps of the BMs were drawn. Figure 3 shows the grain boundary maps of the BMs. In these maps, the high angle boundaries whose misorientation angle is greater than $15^{\circ}$ were denoted by the black lines. As denoted by the red arrows in Fig. 3 (b), the furnace-cooled material had the widest spacing of the interphase and the high angle boundaries, while the water-quenched material had the narrowest spacing of the interphase and the high angle boundaries. In other words, the water-quenched material had the highest density of the grain boundary and the furnace-cooled material had the lowest density of the grain boundary.

Figure 4 shows XRD patterns of the BMs. The Bragg's peaks of each materials show a simple XRD pattern of hcp $\alpha$ phase and no significant difference was found among the three materials. The $\beta$ phase was quiet difficult to be distinguished due to the limited amount of the $\beta$ phase in the BMs. It should be also noted that the width of the peaks obtained at the water-quenched material was wider than those of the as-received material and the furnace-cooled material. This 
result should be attributed to the strains present in the fine $\alpha$ phases caused by the heat treatment as well as a higher density of the high angle boundaries in the water-quenched material.

\subsection{Weld macrostructure}

Figure 5 shows the optical macrographs of the cross section perpendicular to the tool traverse direction of Fig. 5(a) the as-received material joint, (b) the furnace-cooled material joint and (c) the water-quenched material joint. The horizontal and vertical directions of these figures indicate the transverse direction (TD) and the normal direction (ND) of the joints, respectively. The left side and the right side are the advancing and retreating sides, respectively. The basin-shaped SZs are indicated by the etching and no weld defects such as a vacancy can be found in all the joints. However, some limited parts show contaminations at the locations indicated with the black rectangles in Fig. 5(a) and (c) of the as-received and the water-quenched material joints. Detailed observations of these contaminations were conducted as shown in Fig. 6. Figure 6(a) and (b) show the SEM image and the OM image obtained in the rectangle area in Fig. 5(a) and Fig. 5(c), respectively. These contamination areas exhibited a serrated shape and elongated to the TD. The size of the contamination area decreased when the BM has a coarse microstructure. The EDS measurement clarified that the contaminations are due to the wearing of the FSW tool, as shown in Fig. 6(c) to (f). Fig. 6(c) indicates the enlarged SEM images and the element color maps showing the distribution of the Fig. 6(d) Ti, (e) Co and (f) W. The contamination has the coarse grained morphology and it shows the lack of Ti and the concentrations of Co and $\mathrm{W}$. These two elements are the dominant component of the FSW tool used in this study. 


\subsection{Hardness profile of weld}

Figure 7 shows the hardness distribution across the weld at the plate mid-thickness. As far as the hardness values of the BMs are concerned, the as-received, the furnace-cooled and the waterquenched samples were $363 \mathrm{Hv}, 326 \mathrm{Hv}$ and $397 \mathrm{Hv}$, respectively. The hardness of the $\mathrm{BM}$ increased by following an ascending order of the density of the high angle boundaries as shown in Fig. 3. In all the joints, the hardness reached $350 \mathrm{Hv}$ when the measurement position was located at the center of the joint. The hardness values in the SZs of all three joints were similar except for the positions where the contaminations were found. The existence of the contamination produces an extremely higher hardness.

\subsection{Microstructure evolution of weld}

As mentioned in the introduction, the lower thermal conductivity is one of the characteristics and it should provide a thermal distribution. Actually, the morphology of the microstructure in the SZs varies with the change in the observation position in the thickness as shown in Fig. 8. These are the backscattered electron images obtained at Fig. 8(a) the top, (b) the center and (c) the bottom position in thickness at the SZ of the joint for the as-received material. The mixture of both the lamellar structure and the equiaxed $\alpha$ grains can be found in the area near the top surface where the shoulder of the FSW tool contacts. This microstructure morphology is similar to that reported by Liu et al. [5], and Zhou et al. [6,7] which indicated that the peak temperature is 
considered to be just below the $\beta$-transus temperature since the lamellar structure is evolved by the phase transformation from high temperature $\beta$-phase. In other words, the microstructure in this area was evolved by the combination effect of the recrystallization and the phase transformation. When the measurement position shifts further from the top surface, the equiaxed $\alpha$ grain exists as the dominant structure. The microstructures observed at Fig. 8(b) the center and (c) the bottom positions of the SZ were similar to that reported by Kitamura et al. [8], indicating the change in the formation mechanism for the microstructure. This microstructure morphology indicates that the peak temperature was significantly lower than the $\beta$-transus temperature. The fully equiaxed structure implies that the $\alpha$ phase was plastically deformed and the volume fraction of $\alpha$ phase was high enough to form the fully equiaxed microstructure at elevated temperature. The mean $\alpha$ grain size of the center and the bottom position of the SZ was about 1.7 $\mu \mathrm{m}$ and $1.0 \mu \mathrm{m}$, respectively.

Figure 9 shows (a) the area fraction of the equiaxed $\alpha$ grains and (b) the mean $\alpha$ grain size in the SZs as a function of the distance from the top surface. These results were examined based on the backscattered electron images at high magnification as shown in Fig. 8 and the mean grain size was measured by linear intercept method. The changes in the area fraction of the equiaxed $\alpha$ grains were similar among all three joints, that is, the area fraction of the equiaxed $\alpha$ grains increases with the increasing depth of the measurement position. The bottom half of all three joints has the fully-equiaxed $\alpha$ structure with a limited amount of grain boundary structure including the $\beta$ phase. For the mean $\alpha$ grain size, no significant distribution change was found near the top surface of the SZs. On the other hand, all three joints show a decrease in the mean $\alpha$ grain size with the increasing depth of the observation position. The finest equaxed $\alpha$ grain, 
which is $0.7 \mu \mathrm{m}$, can be found at the bottom position of the SZ obtained in the water-quenched material joint. The mean $\alpha$ grain size in the bottom half of the joints has a smaller value in the following order, the water-quenched, the as-received and the furnace-cooled material joints in ascending order. It should be noted that this order is the same as that for the density of the high angle boundaries in the BMs, as shown in Fig. 3.

The crystallographic features should provide the key to clarifying the reason for the difference in the mean $\alpha$ grain size among the three joints, therefore, the EBSD measurements were conducted. Figure 10 shows the orientation color maps of the center and the bottom part of the SZs obtained for all the three joints. The black regions indicate the area where the precise indexing of the EBSD pattern cannot be executed. This implies that the black areas can be regarded as the location of the fine $\beta$ phases. Actually, in the center part of the SZ of the furnacecooled material joint (Fig. 9(b)), the black lines appear with the roughly lined aggregations which can be also found in the BM of the joint as shown in Fig. 2.

Figure 11 shows the TEM images of the SZs obtained at the furnace-cooled material and the water-quenched material joints. As already described above, the microstructure of the SZ composed of the equiaxed $\alpha$ grains with a fine lamellar of $\beta$ phase located at the $\alpha$ boundaries. It is well known that the $\beta$ phase in the Ti-6Al-4V can be preferentially found in the fine lamellar structure at the $\alpha$ grain boundaries [20].

Figure 12 shows the grain boundary maps of all three joints. The black line indicates the high angle boundary whose misorientation angle is larger than $15^{\circ}$ and the green line shows the low angle boundary in which the misorientation angle is between $0.5^{\circ}$ to $15^{\circ}$. In all the maps, the high angle boundaries are the dominant components, however, the low angle boundaries can be 
regarded as the key structure because it has a close relationship with the plastic deformation state. There is one common characteristics for the distribution of the low angle boundaries among all these maps; the low angle boundaries are distributed randomly. Some of the grains have low angle boundaries, while others do not. This feature can be found in some of the severely deformed materials, indicating that the deformation induced boundaries contribute to the microstructure evolution [21,22].

Figure 13 shows the mean high angle grain boundary length per unit area in the center and the bottom parts of the SZ of all three joints calculated using the EBSD data shown in Fig. 12. In order to eliminate an orientation noise, a lower limit boundary misorientation cut-off of $2^{\circ}$ was applied. Based on these scan data, the number of boundaries whose interpixel misorientation is above $15^{\circ}$ was collected and the mean high angle boundary length per unit area was calculated using Eq. (1). The range of measurement error was evaluated by considering the angular resolution $\left(2^{\circ}\right)$ and the interface boundaries that is the surface of the non-measured black island in Fig. 12. These data were shown as the lower and upper error bars in Fig. 13. In all the joints, the mean high angle grain boundary length per unit area at the bottom part of the SZ was larger than that of the center part of the SZ. This tendency well agrees with the grain size distribution shown in Fig. 9 (b). The high angle grain boundary length per unit area in the bottom part of the $\mathrm{SZ}$ in the as-received material joint, the furnace-cooled material joint and the water-quenched material joint were $5.4 \mu \mathrm{m}^{-1}, 4.1 \mu \mathrm{m}^{-1}$ and $6.6 \mu \mathrm{m}^{-1}$, respectively. This result suggests that the grain boundaries with higher misorientation angles are preferentially found in the joint with the BM which has the larger amount of high angle boundaries. Consequently, it can be concluded that the grain refinement is actually accelerated by the finer microstructure in the BM. 
The significant findings in this paper are the following two points:

(1) the microstructure distribution in the thickness at the SZ, and

(2) the accelerated grain refinement due to the adoption of the finer microstructure in the BM.

The former has been discussed by Lienert [9] and also the authors' previous paper [23] in which the reason for the distribution is mainly due to the temperature gradient in the thickness. The lower temperature with plastic deformation provides a finer microstructure via recrystallization and grain growth. According to the authors' knowledge, the latter (2) should be a new finding. The possible mechanisms for the microstructure changes in the Ti-6Al-4V are the phase transformation from the $\beta$ phase and the recrystallization. As mentioned with Fig. 8 , the morphology of the $\alpha$ grains indicates the phase transformation should be limited since the elongated morphology is generally formed by the transformation in this alloy without plastic working. Also, this is reasonable because the peak temperature is significantly lower than that of the $\beta$-transus temperature. The relationship between the $\beta$-transus and the peak temperature has also been pointed out by Kitamura et al. [8]. This means that the recrystallization is the dominant phenomenon. In addition, it is well known that the fine grained structure as the initial microstructure accelerated the recrystallization and also the resultant grain size became finer $[24,25]$. The mechanism of the acceleration is considered to be the acceleration of the inhomogeneous plastic deformation by the constraint effect of the grain boundaries [26]. This means that the finer distribution of the inclusions containing the $\beta$ phase can also contribute to the grain refinement. Consequently, the finer microstructure in the BM contributes the grain refinement of the resultant microstructure in the FSW joints, when the process is conducted at an adequately low temperature. 


\section{Conclusions}

This study examined the effect of the initial microstructure on the microstructural evolution during the FSW of Ti-6Al-4V plates. The BMs with three kinds of morphologies that are an equiaxed $\alpha$ structure, a coarse lamellar structure with less high angle boundaries and a fine $\alpha^{\prime}-$ martensite structure were underwent by FSW and it clarified the change in the microstructure of the FSW joints. The butt welding by FSW with a relatively slower tool rotation rate $(150 \mathrm{rpm})$ was successfully conducted by keeping the temperature at the top surface lower than the $\beta$ transus temperature. The FSW produced joints without weld cracks except for a small amount of contamination due to the wearing of the FSW tool. The contamination decreased when the BM had coarse lamellar structure. The following conclusions can be drawn.

(1) The microstructures in the SZ showed a distribution in thickness for all three joints. The area near the top surface where the FSW tool was plunged had a mixture of the lamellar $\alpha+\beta$ structure with the equiaxed $\alpha$ grains. The area fraction of the lamellar $\alpha+\beta$ structure decreased with the increasing depth of the observation position, and the bottom half of the joints showed a fully equiaxed $\alpha$ structure. The mean $\alpha$ grain size also decreased. This is due to the peak temperature gradient in the thickness during the FSW process.

(2) When the mean $\alpha$ grain size was compared at the same depth, no significant change among the three joints could be found near the top surface; whereas in the bottom half of the joints, the equiaxed $\alpha$ grain size decreased with the increasing density of the high angle boundaries in the $\mathrm{BM}$. The recrystallization is the key phenomenon for the microstructure evolution in the bottom half where the fully equiaxed grains were evolved and the initial grain boundary provides the preferable site for the formation of recrystallized grains. 


\section{Acknowledgement}

This work was conducted as a part of the Aerospace Industry Innovation Program-Advanced Materials \& Process Development for Next-Generation Aircraft Structures project under contract with the RIMCOF Research Center of Materials Process Technology Center, established by the Ministry of Economy, Trade and Industry (METI) of Japan. Additionally, this study was supported by the Japan Science and Technology Agency (JST) under Collaborative Research Based on the Industrial Demand, "Heterogeneous Structure Control: Towards Innovative Development of Metallic Structural Materials", The Global COE Program and a Grant-in-Aid for

Science Research from the Japan Society for Promotion of Science. The authors are grateful to Prof. Nakai, Tohoku University, in Japan for his discussion. 


\section{References}

[1]W.M. Thomas, D.E. Nicholas, J.C. Needham, M.G. Murch, P. Templesmith, C.J. Dawes, GB Patent Application No. 9125978.8, Dec. 1991.

[2]A.J. Ramirez, M.C. Juhas, "Microstructure evolution in Ti-6Al-4V friction stir welding", Mater. Sci. Forum, 426-432(2003), pp.2999-3004.

[3]Y. Zhang, Y.S. Sato, H. Kokawa, S.H.C. Park, S. Hirano, "Microstructural characteristics and mechanical properties of Ti-6Al-4V friction stir welds", Mater. Sci. Eng. A, 485 (2008), pp. $448-455$.

[4]J. Su, J. Wang, R.S. Mishra, R. Xu, J.A Baumann, "Microstructure and mechanical properties of a friction stir processed Ti-6Al-4V alloy", Mater. Sci. Eng. A, 573 (2013), pp. 67-74.

[5]H.J Liu, L. Zhou, Q.W Liu, "Microstructural characteristics and mechanical properties of friction stir welded joints of Ti-6Al-4V titanium alloy”, Mater. Des., 31 (2010), pp. 1650-5.

[6]L. Zhou, H.J Liu, Q.W Liu, "Effect of rotation speed on microstructure and mechanical properties of Ti-6Al-4V friction stir welded joints", Mater. Des., 31 (2010), pp. 2631-6.

[7]L. Zhou, H.J Liu, P. Liu, Q.W Liu, "The stir zone microstructure and its formation mechanism in Ti-6Al-4V friction stir welds", Scr. Mater., 61 (2009), pp. 596-9.

[8]K. Kitamura, H. Fujii, Y. Iwata, Y.F. Sun, Y. Morisada, "Flexible control of the microstructure and mechanical properties of friction stir welded Ti-6Al-4V joints", Mater. Des., 46 (2013), pp.348-353. 
[9]T.J. Lienert, "Microstructure and mechanical properties of friction stir welded Titanium alloys" in Friction Stir Welding and Processing, edited by R.S. Mishra, M.W. Mahoney, AMS International, 2007, pp.123-154.

[10]P. D. Edwards, M. Ramulu, "Investigation of microstructure, surface and subsurface characteristics in titanium alloy friction stir welds of varied thicknesses", Sci. Technol. Weld. Join., 14 (2009), pp. 476-483.

[11]F. Findik, "Recent developments in explosive welding", Mater. Des., 32 (2011), pp. 10811093.

[12]N. Kahramana, B. Gulencb, F. Findik, "Corrosion and mechanical-microstructural aspects of dissimilar joints of Ti-6Al-4V and Al plates", Inter. J. Impact Eng., 34 (2007), pp. 1423-1432.

[13]N. Kahramana, B. Gulenc, F. Findik, "Joining of titanium/stainless steel by explosive welding and effect on interface" J. Mater. Process. Technol., 169 (2005), pp. 127-133

[14]H. Uzun, C. D. Donne, A. Argagnotto, T. Ghidini, C. Gambaro, "Friction stir welding of dissimilar Al 6013-T4 to X5CrNi18-10 stainless steel”, Mater. Des., 26 (2005), pp. 41-46.

[15]G. Cam, "Friction stir welded structural materials: beyond Al-alloys", Inter. Mater. Reviews, 56 (2011), pp. 1-48.

[16]R.S. Mishra, Z.Y. Ma, "Friction stir welding and processing". Mater. Sci. Eng. R, 50 (2005), pp.1-78.

[17]K.V. Jata, S.L. Semiatin, "Conscious dynamic recrystallization during friction stir welding of high strength aluminum alloy", Scr. mater., 43 (2000), pp.743-9. 
[18]Y.S. Sato, H. Kokawa, M. Enomoto, S. Jogan, T. Hashimoto, "Precipitation sequence in friction stir weld of 6063 aluminum during aging", Metall. Mater. Trans. A, 30A (1999), pp.3125-30.

[19]R. Ding, Z.X. Guo, A. Wilson, "Microstructural evolution of a Ti-6Al-4V alloy during thermomechanical processing", Mater. Sci. Eng. A, 327 (2002), pp. 233-245.

[20]G. Welsch, R. Boyer, E.W. Collings, "Materials Properties Handbook: Titanium Alloys", ASM International, 1993.

[21]S.Y. Mironov, G.A. Salishchev, M.M. Myshlyaev, R. Pippan, "Evolution of misorientation distribution during warm 'abc' forging of commercial-purity titanium", Mater. Sci. Eng. A, 418 (2006), pp. 257-267.

[22]V.V. Stolyarov, Y.T. Zhu, T.C. Lowe, R.K. Islamgaliev, R.Z. Valiev, "A two step SPD processing of ultrafine-grained titanium", NanoStructured Mater., 11 (1999), pp.947-954.

[23]S. Yoon, R. Ueji, H. Fujii, "Effect of rotation rate on microstructure and texture evolution during friction stir welding of Ti-6Al-4V plates", Mater. Character., 106 (2015),pp.352-358.

[24]J.P. Sah, G.J. Richardson, C.M. Sellars, "Grain-Size Effects during Dynamic Recrystallization of Nickel", Mater. Sci.Tech., 8 (1974), pp.325-331.

[25]M. El Wahabi, L. Gavard, F. Montheillet, J.M. Cabrera, J.M. Prado, "Effect of initial grain size on dynamic recrystallization in high purity austenitic stainless steels", Acta Mater., 53 (2005), pp.4605-4612. 
[26]M.F. Ashby, I.G. Palmer, "The dragging of solid particles through metals by grain boundaries" Acta Metall., 15 (1967), pp.420-3. 


\section{Captions}

Fig. 1 Backscattered electron image of (a) as-received material (b) furnace-cooled material and (c) water-quenched material.

Fig. 2 Orientation color map of (a) as-received material (b) furnace-cooled material and (c) water-quenched material.

Fig. 3 Grain boundary map of (a) as-received material (b) furnace-cooled material and (c) waterquenched material, high angle boundaries are indicated by black lines.

Fig. 4 X-ray diffraction patterns of as-received material, furnace-cooled material and waterquenched material.

Fig. 5 Macrographs of cross-sections perpendicular to tool traverse direction of FSWed Ti-6Al4V plates; (a) as-received material, (b) furnace-cooled material and (c) water-quenched material joint.

Fig. 6 Microstructural features of contaminated microstructure area; (a) SEM image of rectangle area in Fig. 5 (a) of as-received material joint, (b) OM image of rectangle area in Fig. 5 (c) of water-quenched material joint, (c) SEM image, EDS elemental maps of (d) Ti, (e) Co and (f) W of rectangle area in Fig. 5 (a) of as-received material joint.

Fig. 7 Hardness distribution of FSWed plates along center-line in thickness.

Fig. 8 Microstructure of SZ obtained at as-received material joint; (a) top surface (b) SZ center and (c) bottom surface. 
Fig. 9 Microstructural characteristics in the SZ; (a) area fraction of equiaxed $\alpha$ grain to lamellar structure along plate thickness and (b) equiaxed $\alpha$ grain size distribution along plate thickness.

Fig. 10 Orientation color map of SZ center; (a) as-received material joint, (b) furnace-cooled material joint, (c) water-quenched material joint and orientation color map of bottom part of SZ; (d) as-received material joint, (e) furnace-cooled material joint, (f) water-quenched material joint.

Fig. 11 TEM images of the SZ; (a) furnace-cooled material joint and (b) water-quenched material joint

Fig. 12 Grain boundary map of SZ center; (a) as-received material joint, (b) furnace-cooled material joint, (c) water-quenched material joint and grain boundary map of bottom part of SZ; (d) as-received material joint, (e) furnace-cooled material joint, (f) water-quenched material joint, low angle boundaries and high angle boundaries are indicated by green and black lines, respectively.

Fig. 13 Mean high angle grain boundary length per unit area in center and bottom part of SZ of all three joints. 

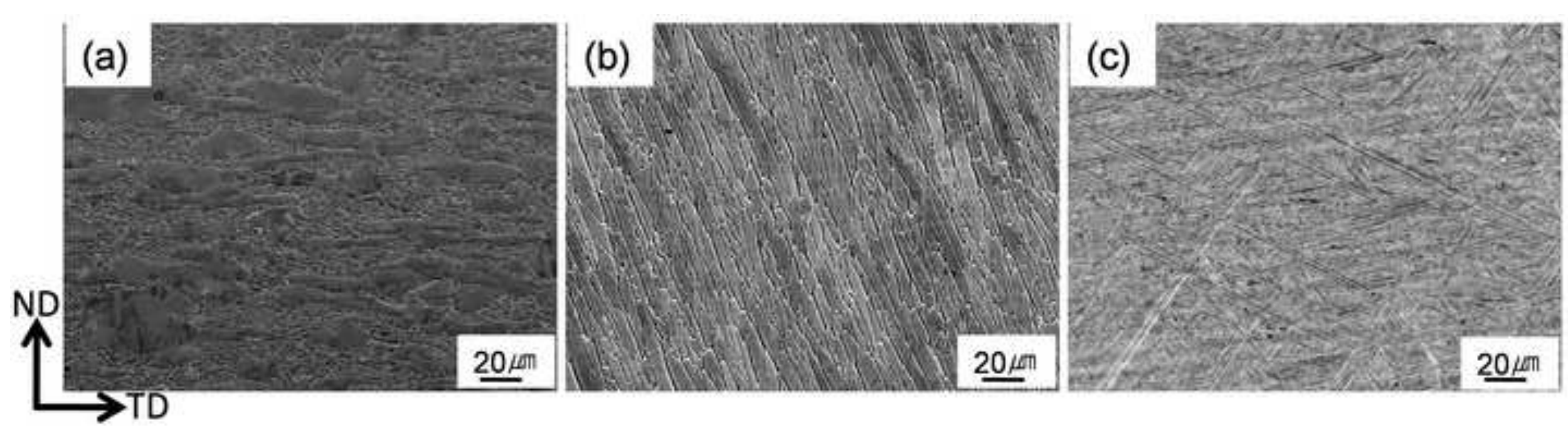

Oب10 

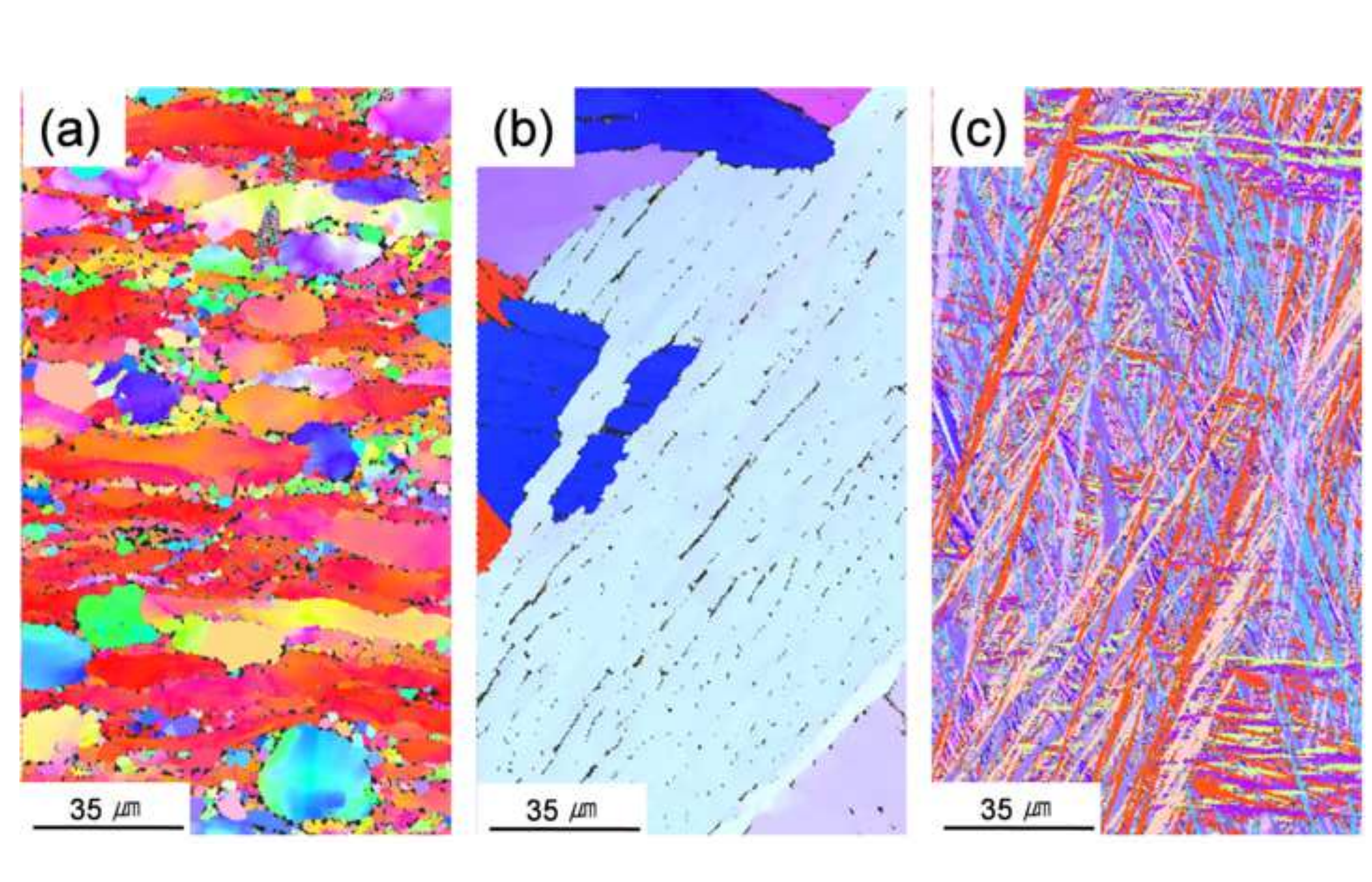

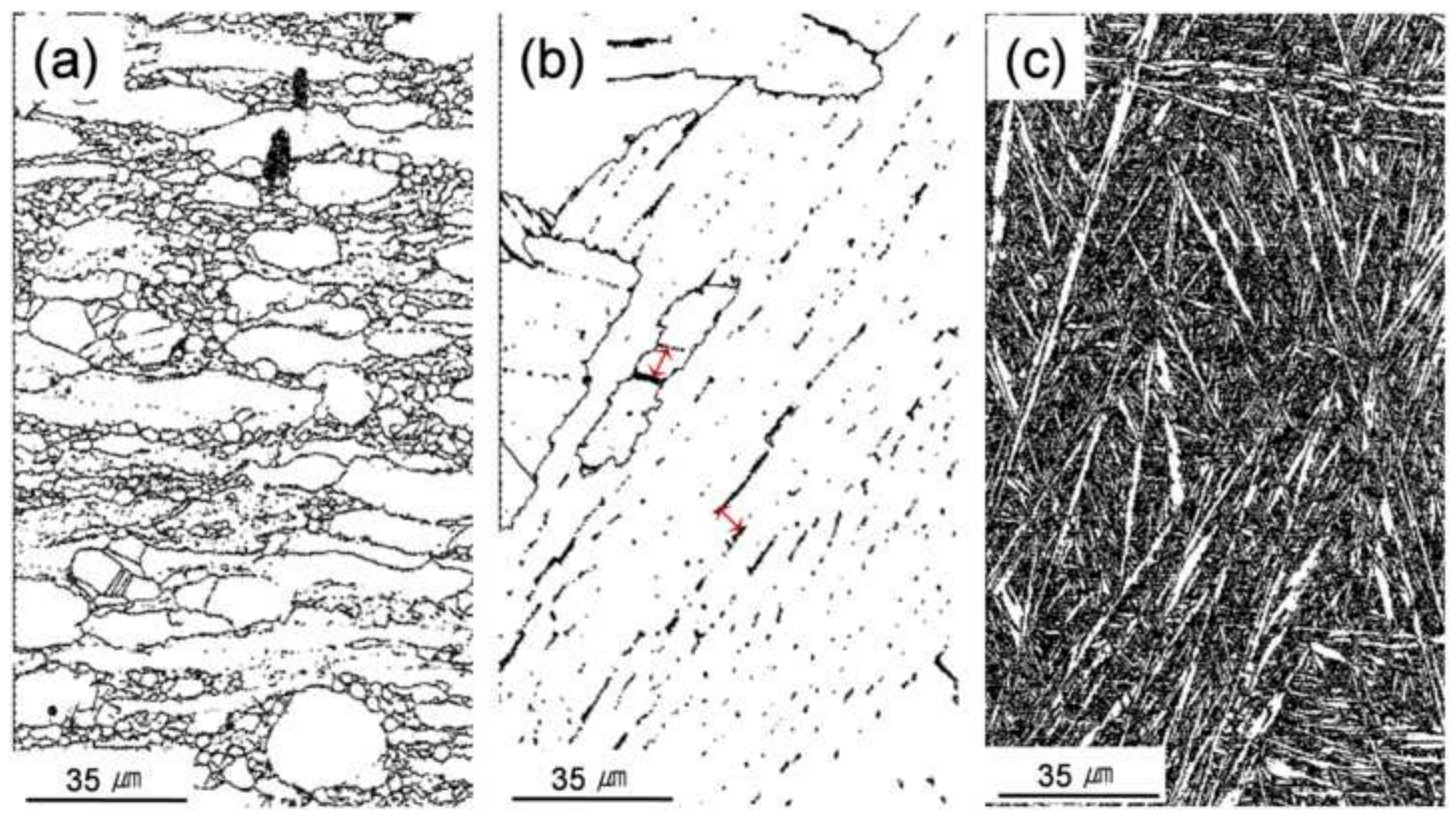


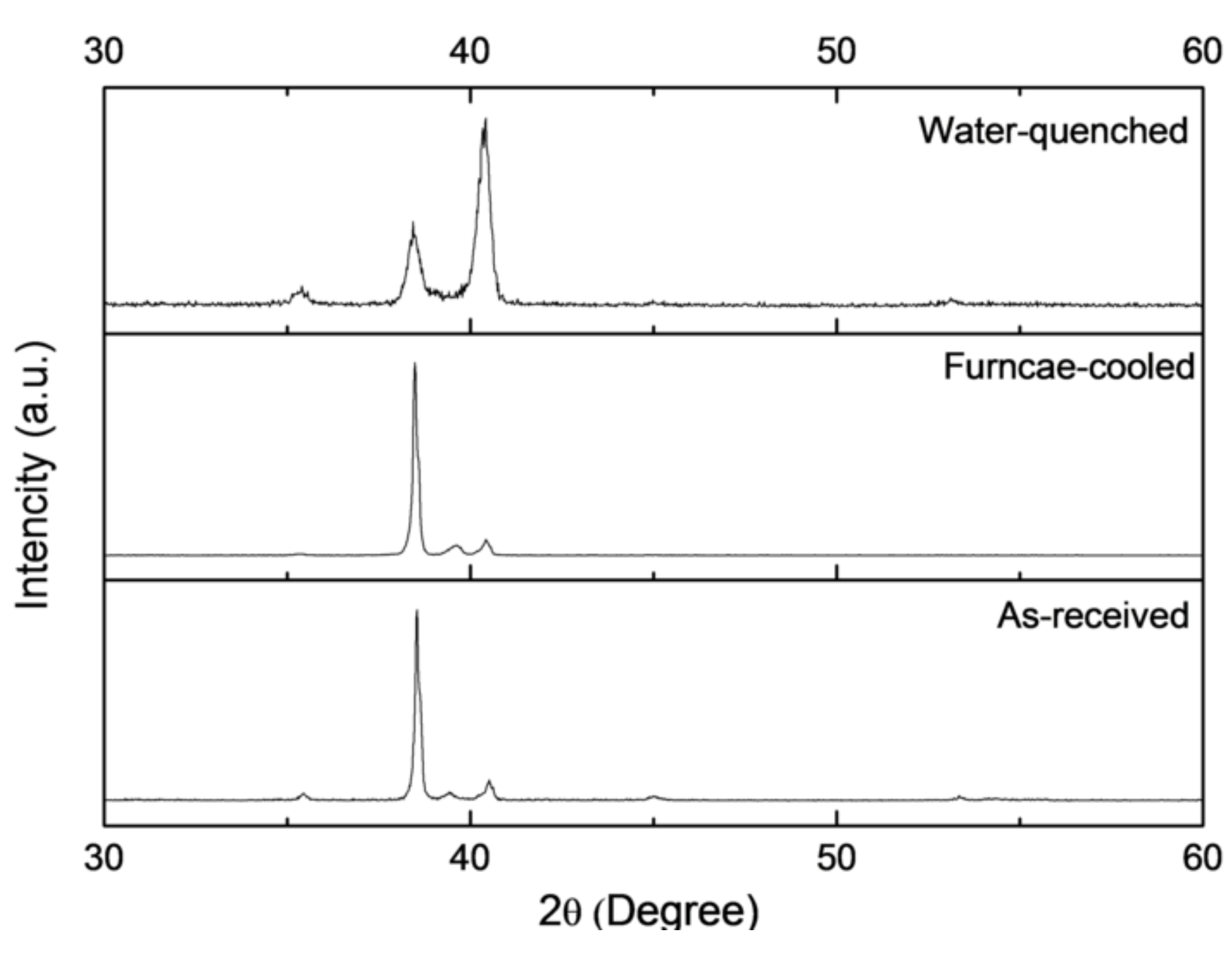

fig. 4.ti

0

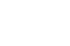

. 
(a)

\section{$\square$}

$2 \mathrm{~mm}$

(b)

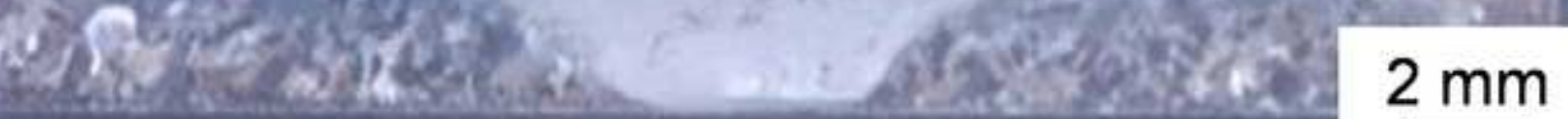
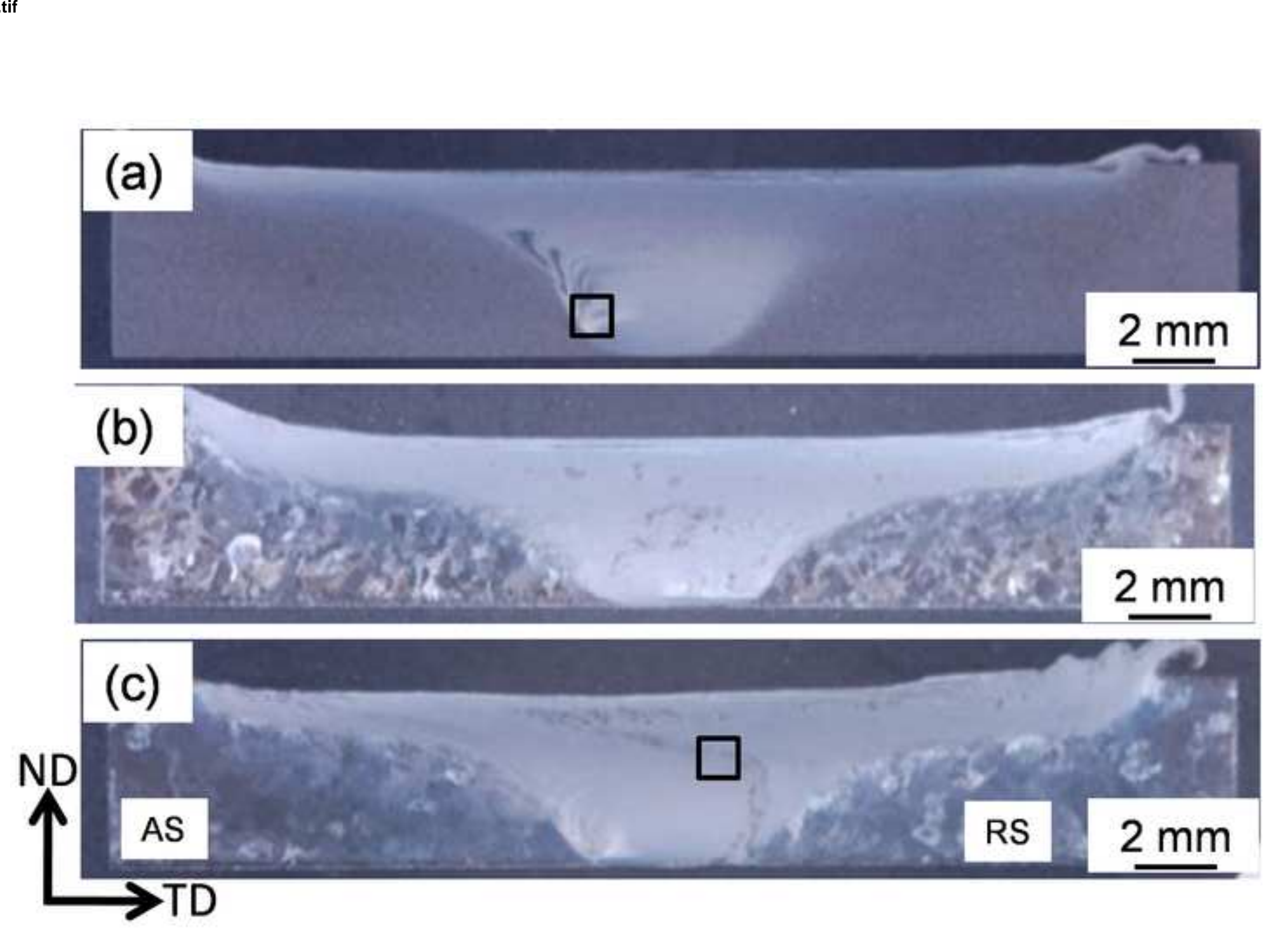

(c)

$\mathrm{ND}$

AS

RS

$2 \mathrm{~mm}$

$\rightarrow$ TD

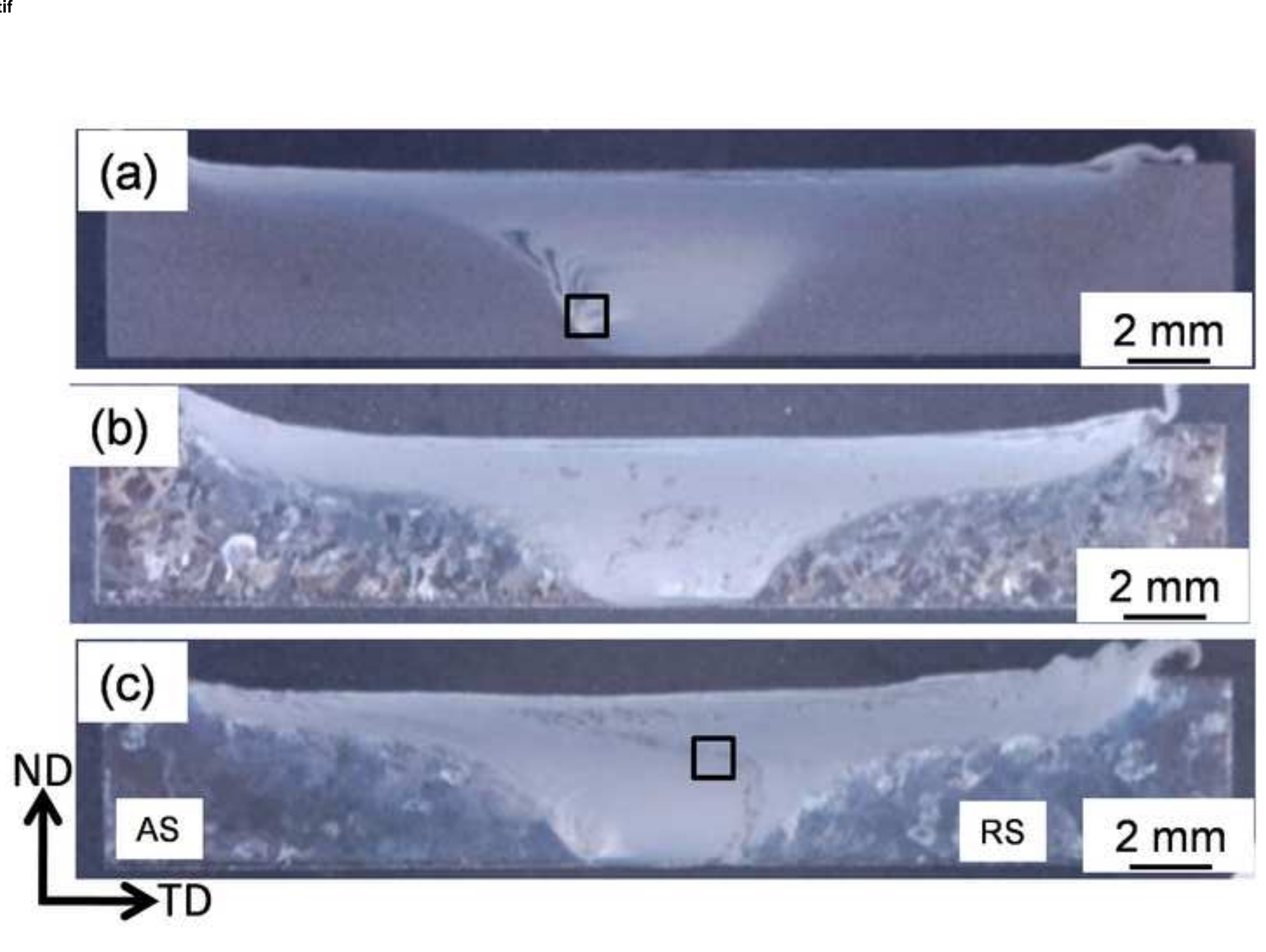

.



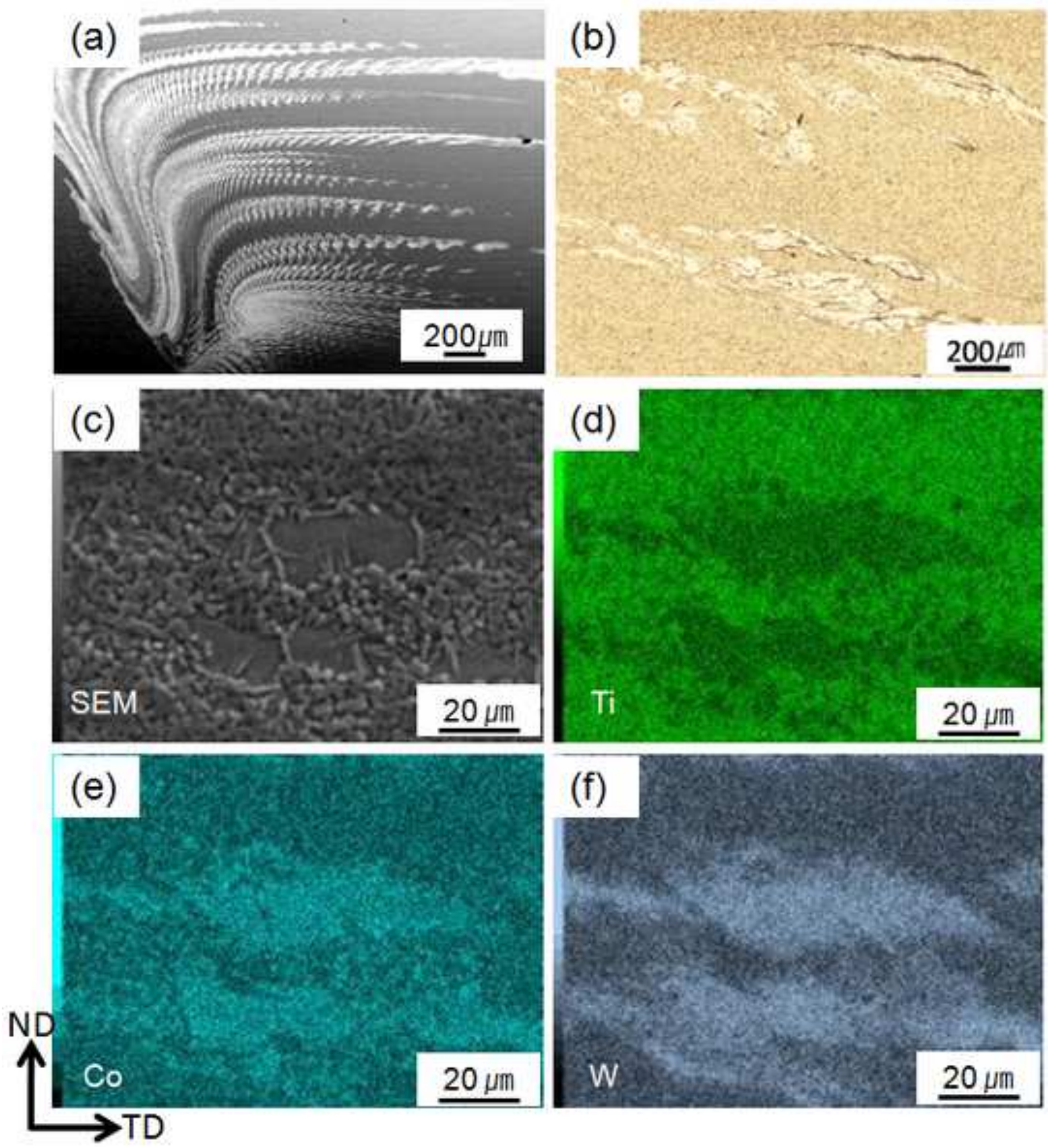

(f)

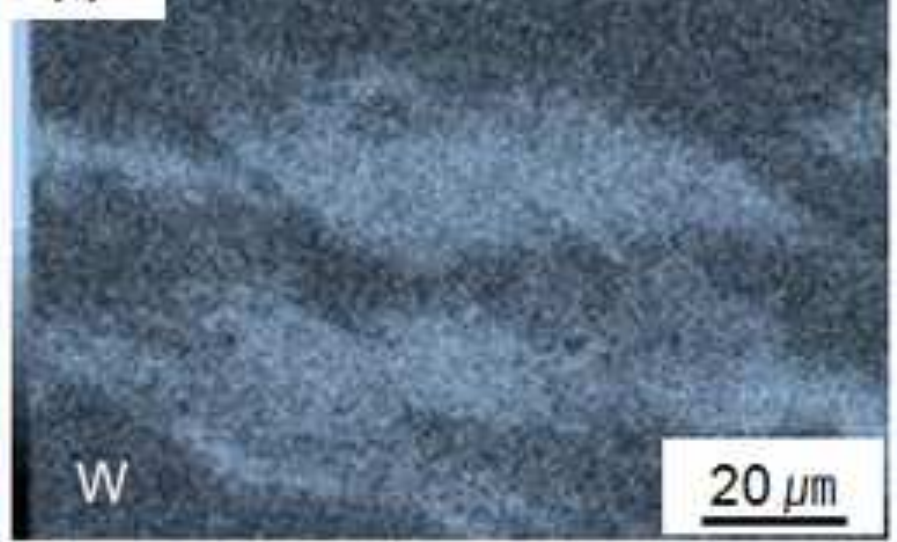

$20 \mu \mathrm{m}$ 


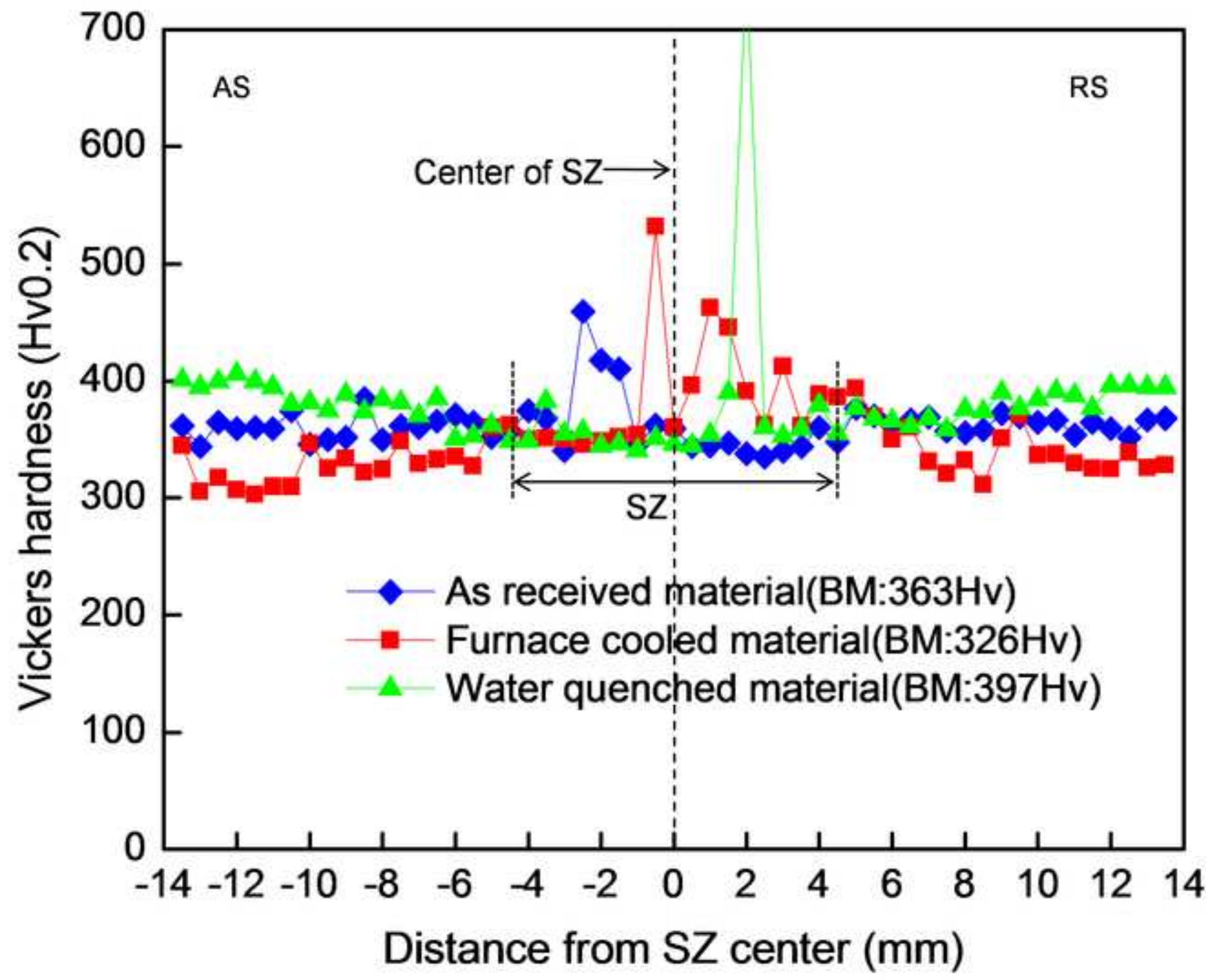



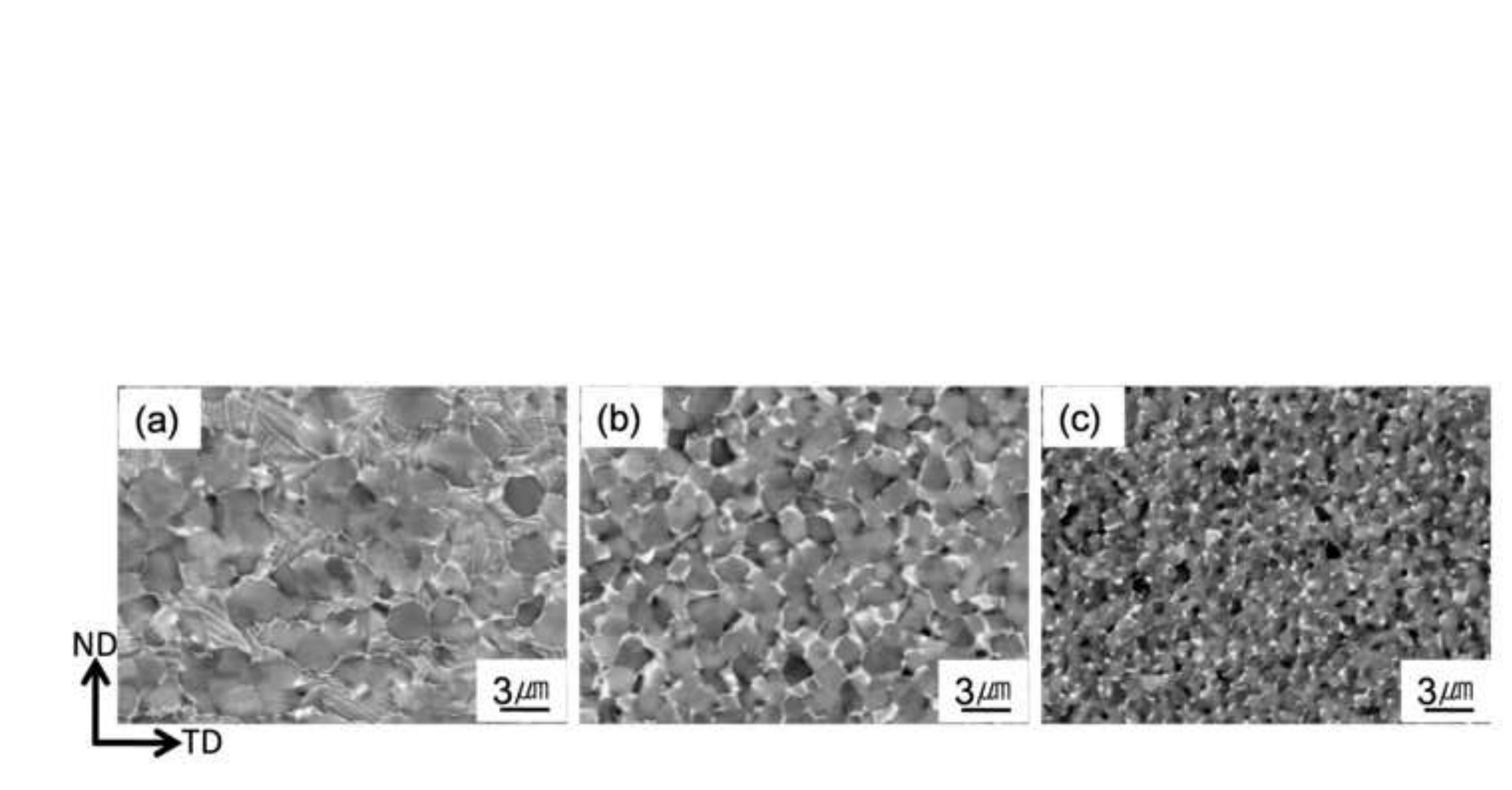

(c)
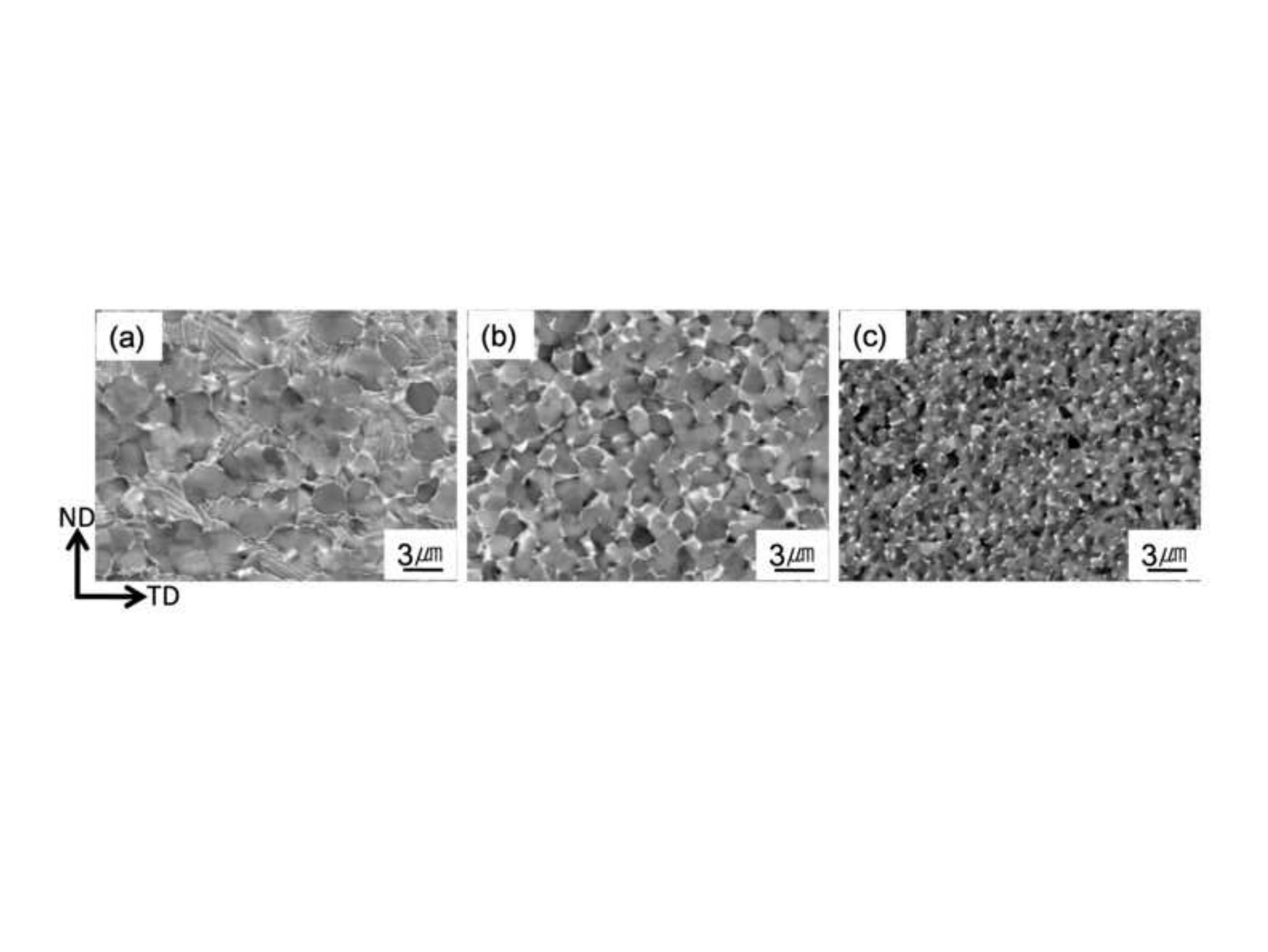

.

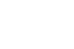
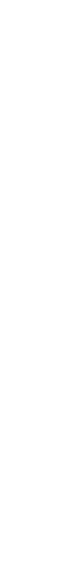
(a)

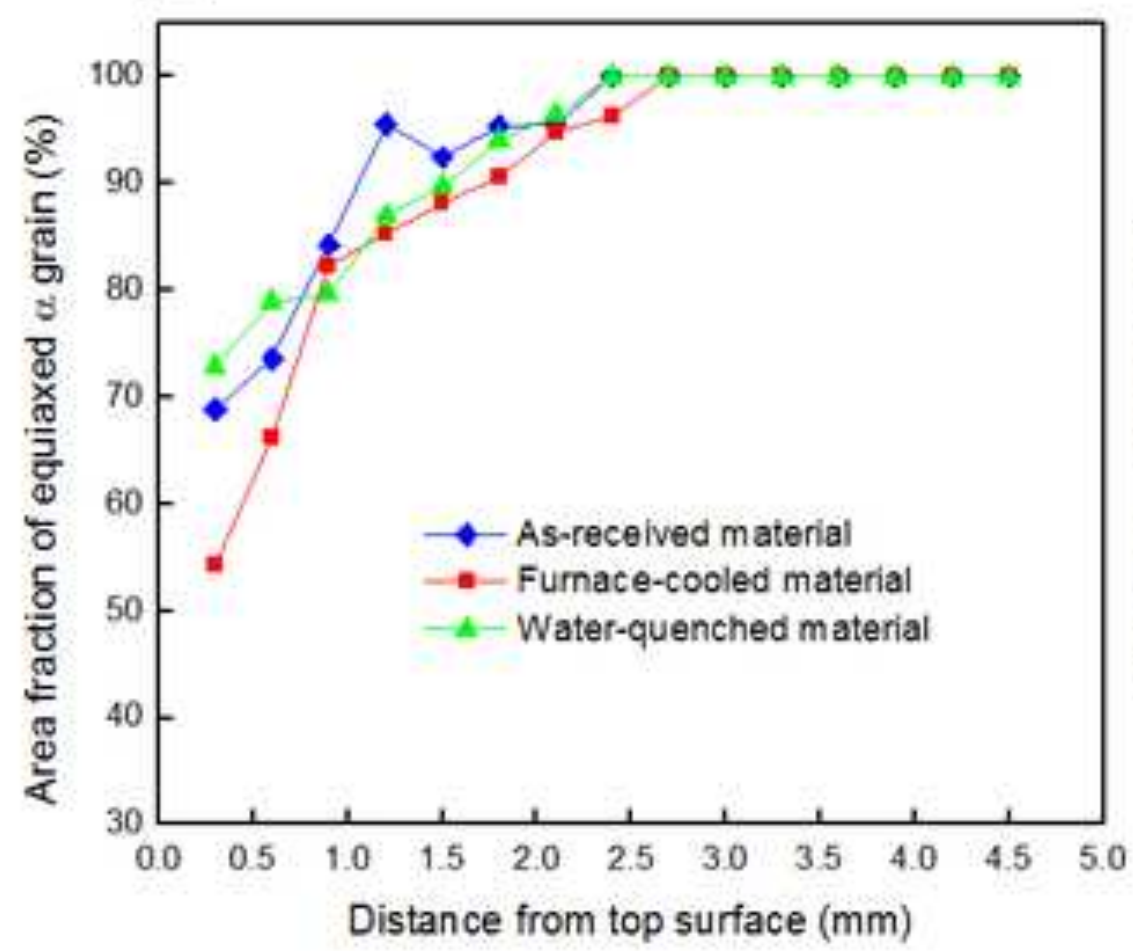

(b)

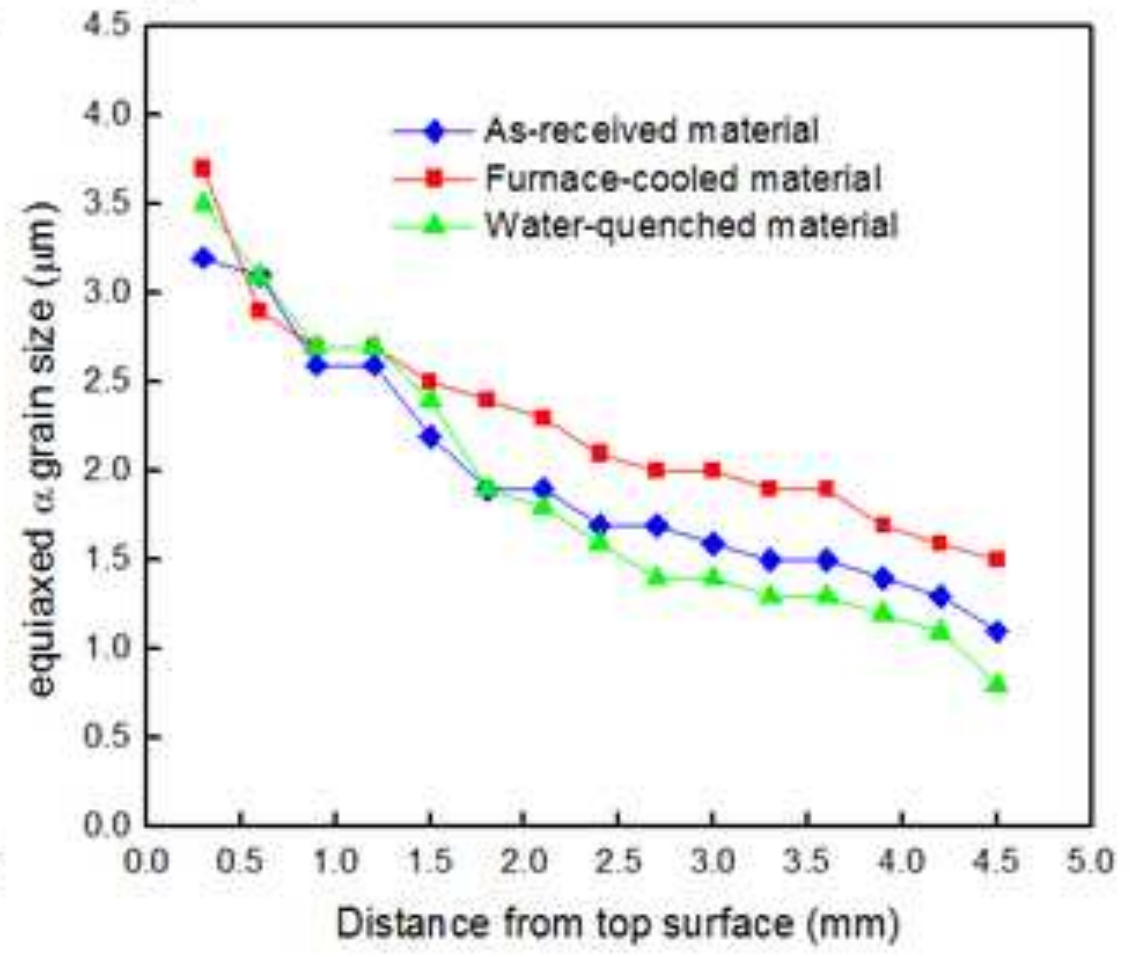




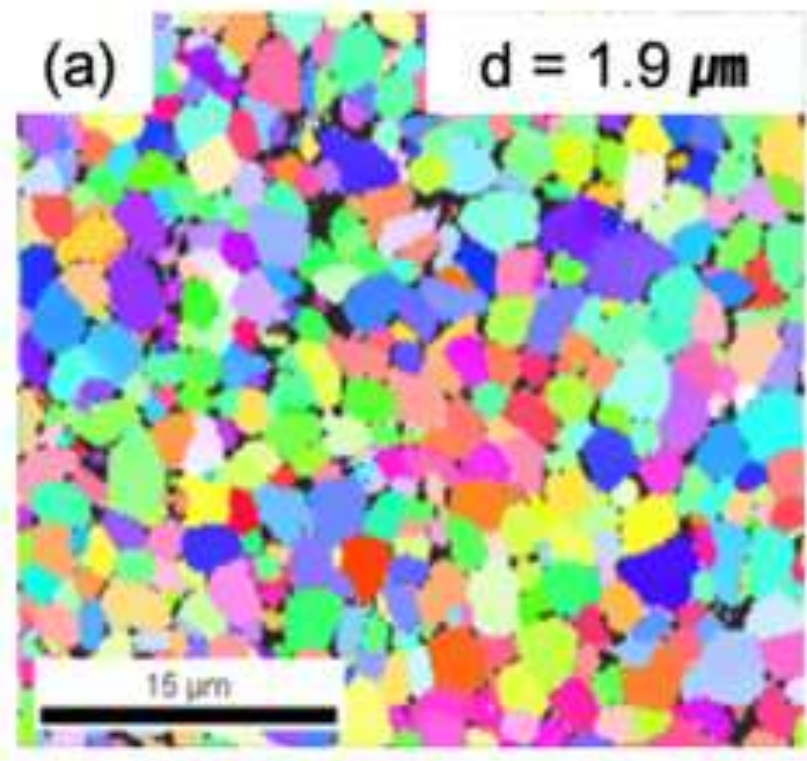

(d) $\mathrm{d}=0.9 \mu \mathrm{m}$

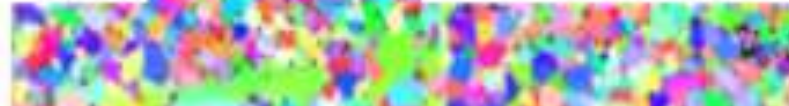

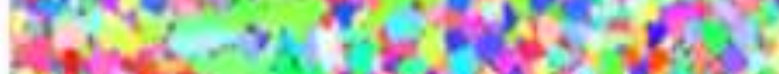

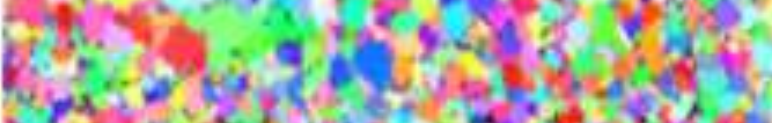

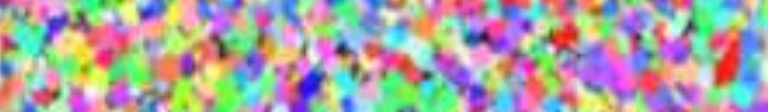

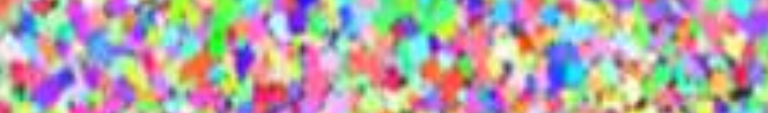

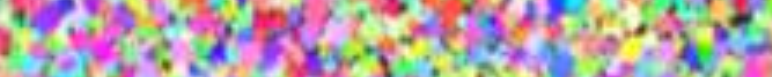
4. 3 .

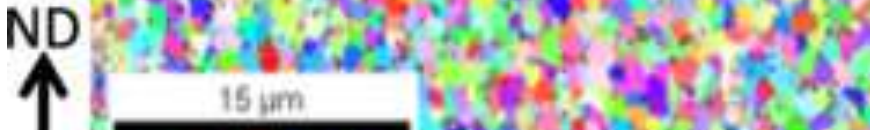
$\Rightarrow T D$ (b)

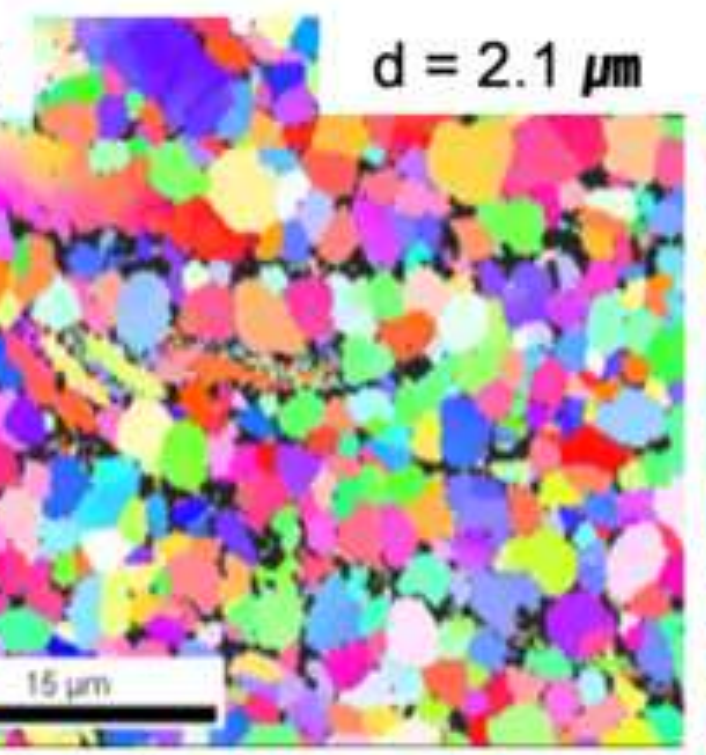

(e) $17=1.1 \mu \mathrm{m}$

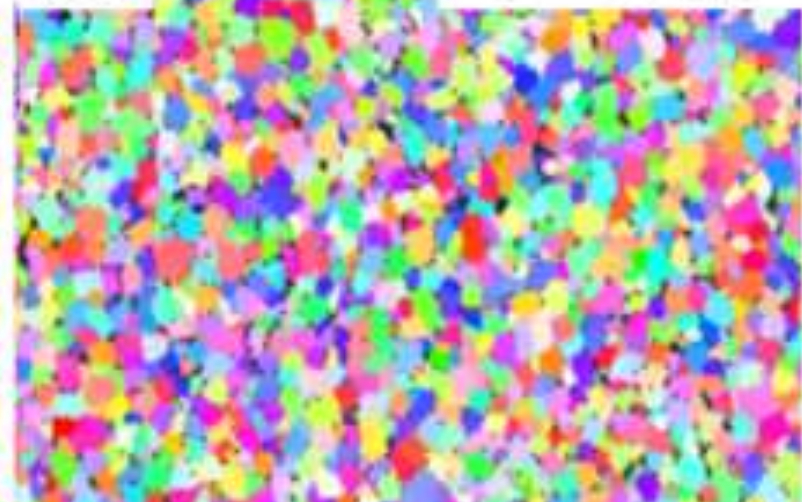

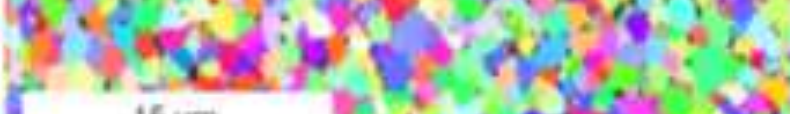

$$
15 \mathrm{um}
$$

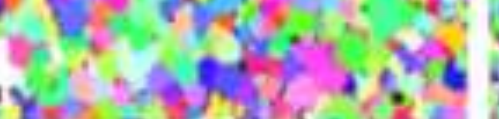

(c) $\mathrm{d}=1.8 \mu \mathrm{m}$

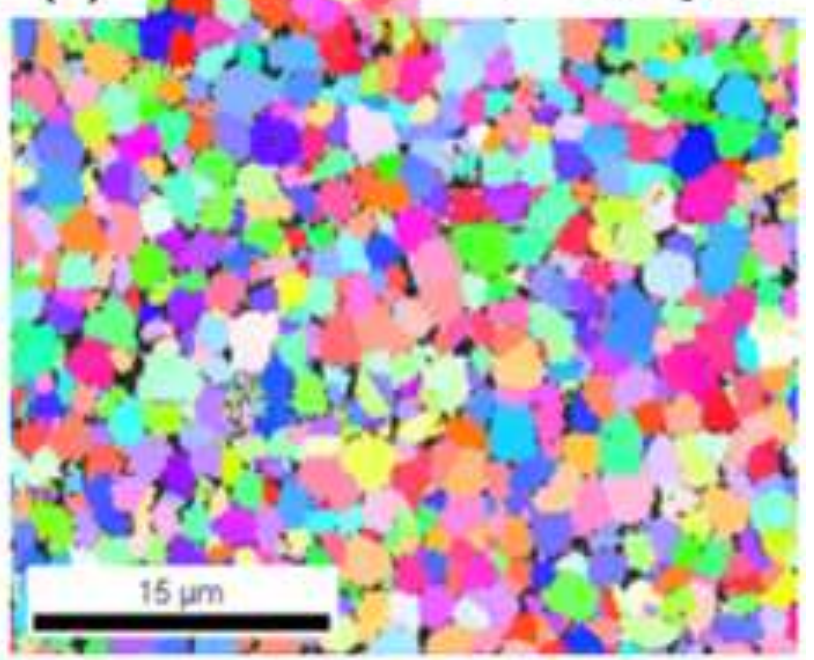

(f) $\left.\mathrm{g}^{2} \mathrm{y} ; \mathrm{d}\right) \mathrm{d}=0.7 \mu \mathrm{m}$

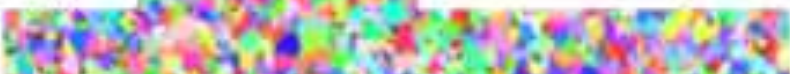

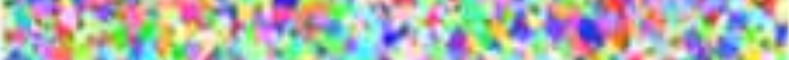

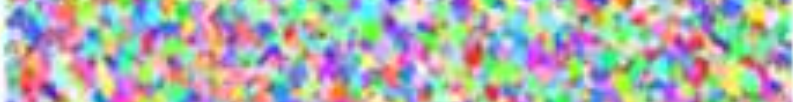

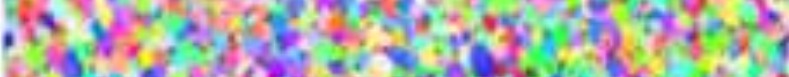

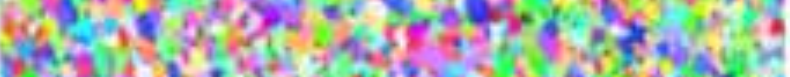

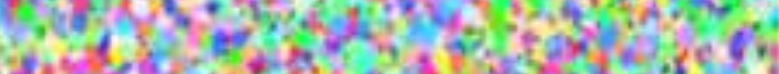

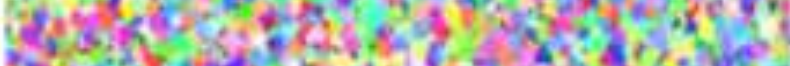

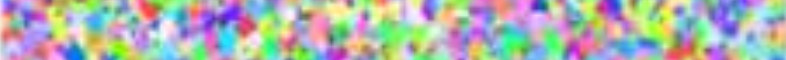

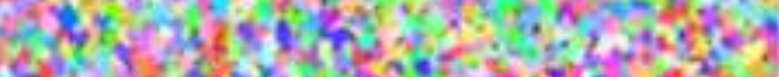

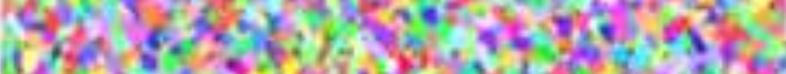

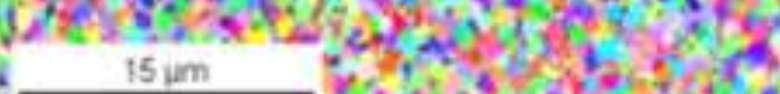

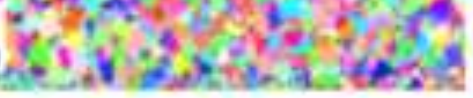




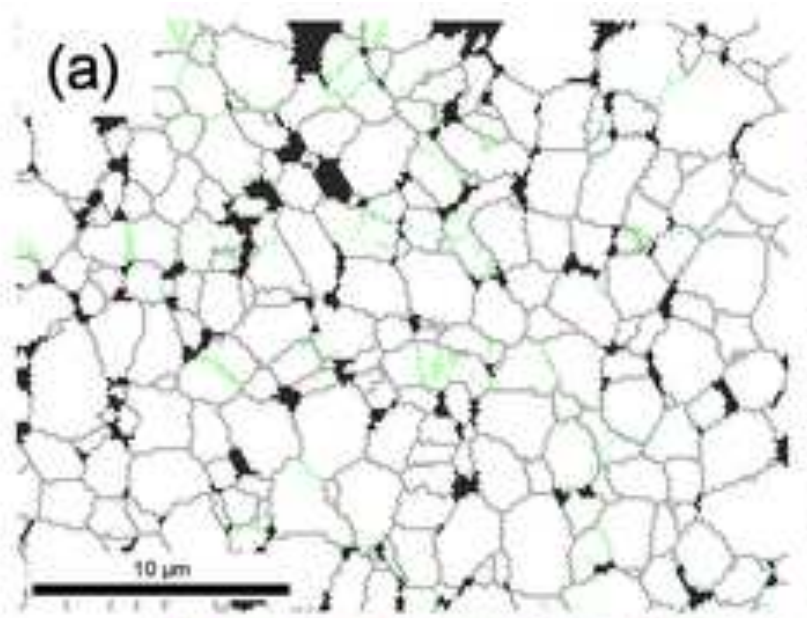

(d)

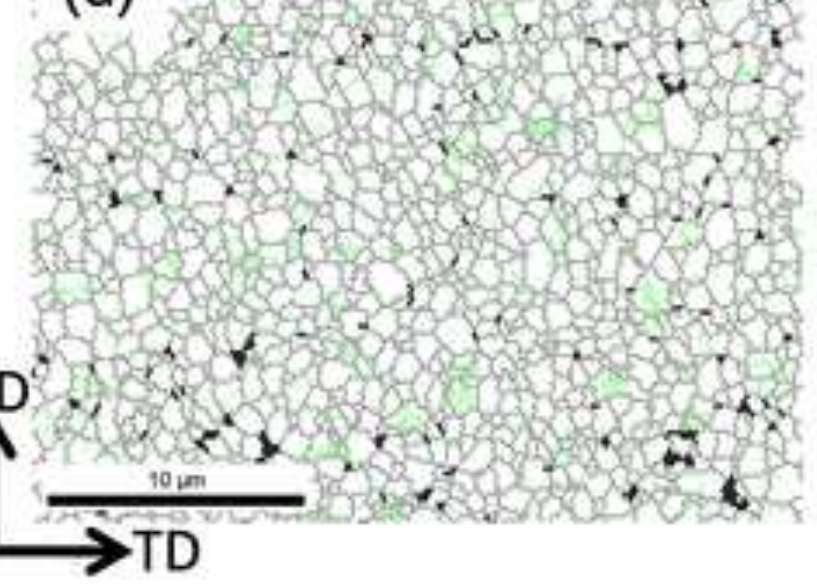

(b) $x+2,+4+2+2$

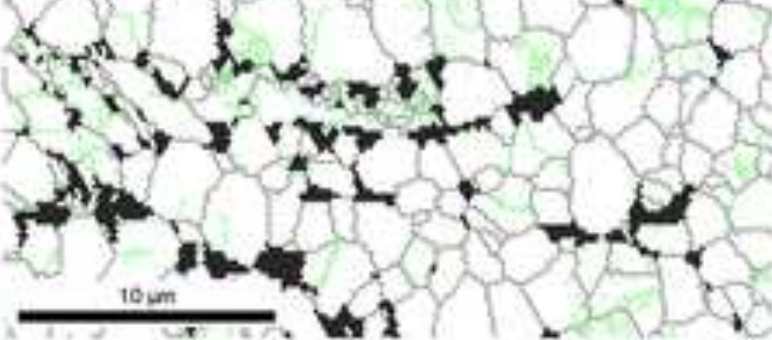

(e) 5,03 (3) Hor on a 30 $13^{2} \times$ aी

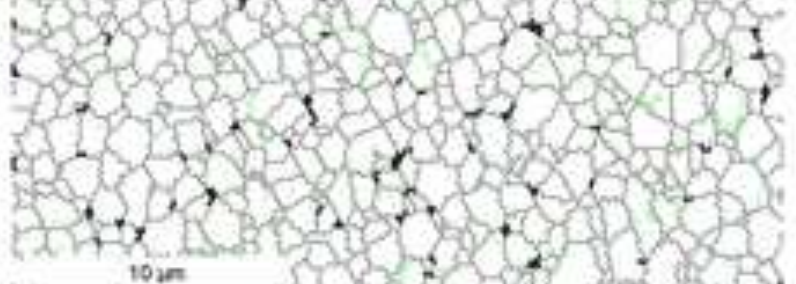

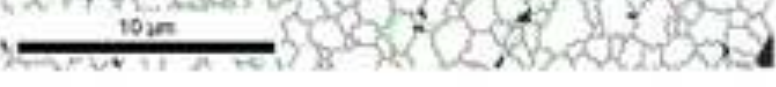

(c) $x^{2}+0^{\circ}+4 y^{2}$

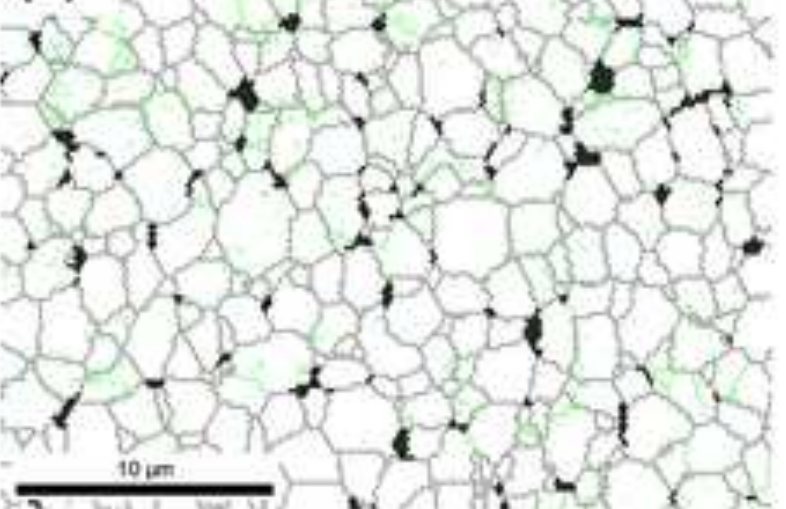

(f)

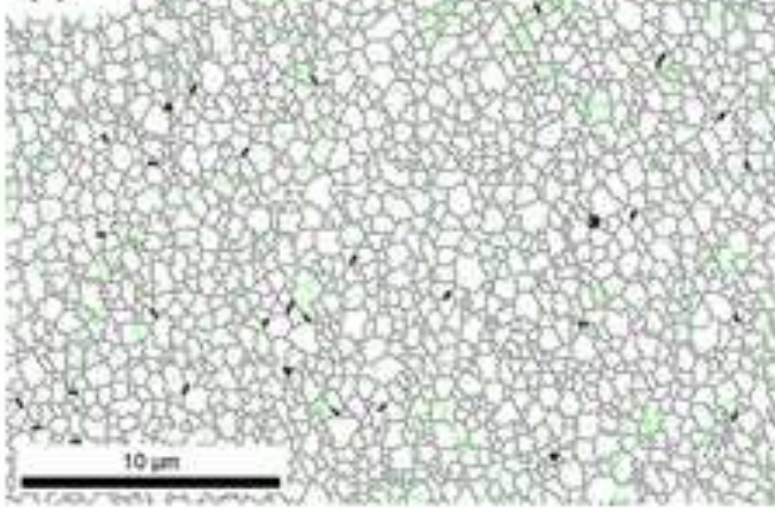




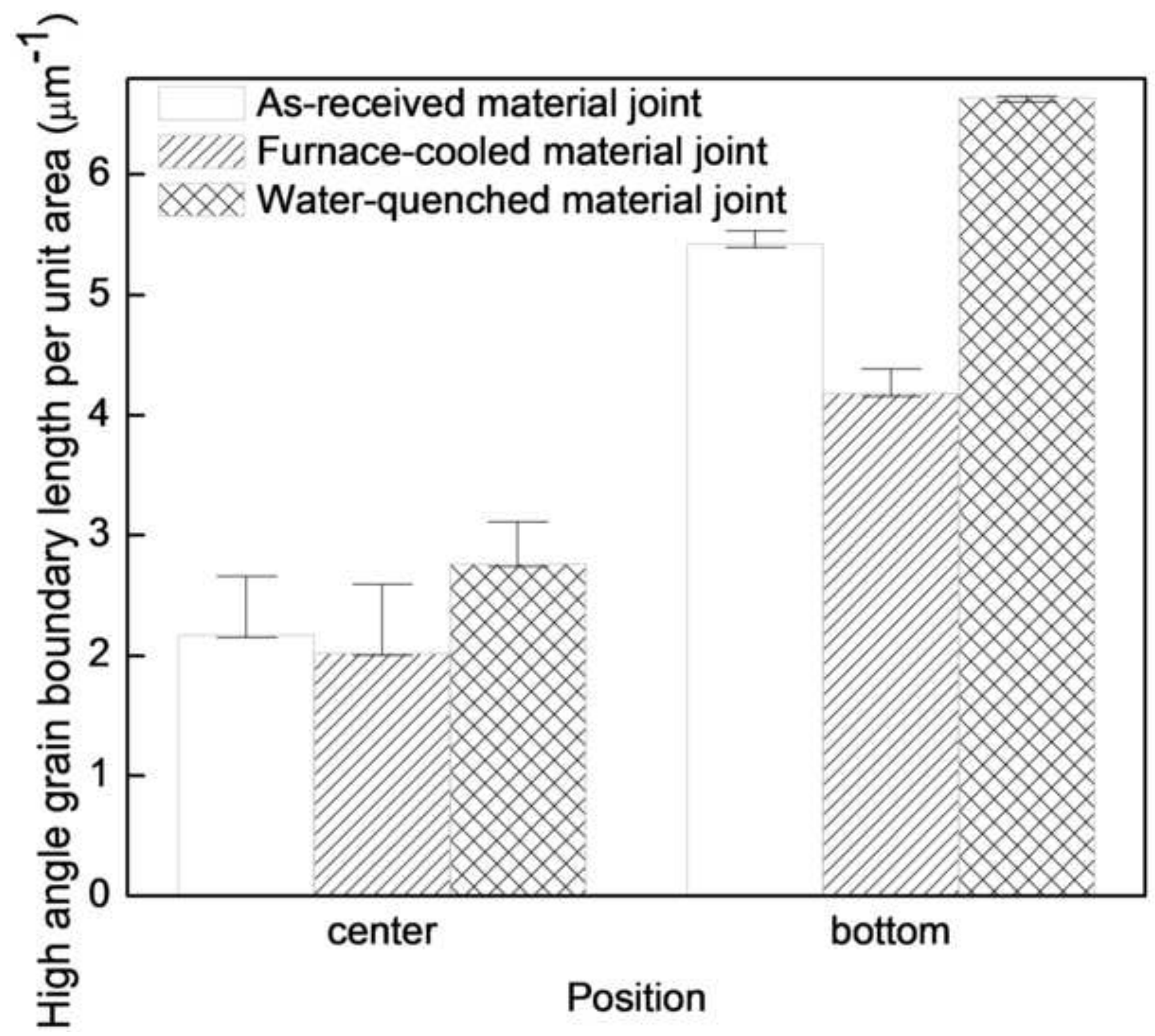




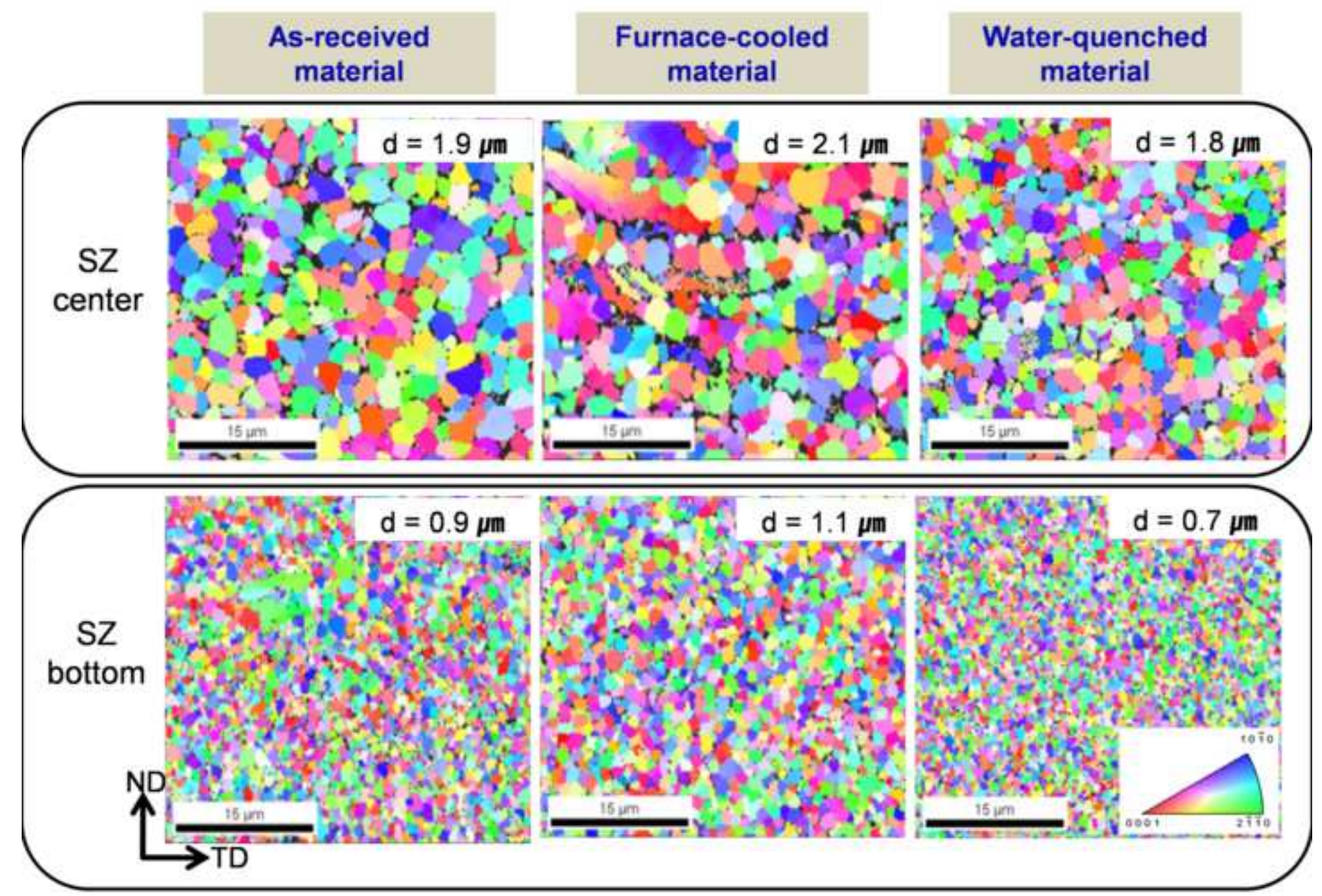

